\title{
Testing of a Predictive Control Strategy for Balancing Renewable Sources in a Microgrid
}

Marinelli, Mattia; Sossan, Fabrizio; Costanzo, Giuseppe Tommaso; Bindner, Henrik W.

Published in:

IEEE Transactions on Sustainable Energy

Link to article, DOI:

10.1109/TSTE.2013.2294194

Publication date:

2014

Link back to DTU Orbit

Citation (APA):

Marinelli, M., Sossan, F., Costanzo, G. T., \& Bindner, H. W. (2014). Testing of a Predictive Control Strategy for Balancing Renewable Sources in a Microgrid. IEEE Transactions on Sustainable Energy, 5(4), 1426-1433. https://doi.org/10.1109/TSTE.2013.2294194

\section{General rights}

Copyright and moral rights for the publications made accessible in the public portal are retained by the authors and/or other copyright owners and it is a condition of accessing publications that users recognise and abide by the legal requirements associated with these rights.

- Users may download and print one copy of any publication from the public portal for the purpose of private study or research.

- You may not further distribute the material or use it for any profit-making activity or commercial gain

- You may freely distribute the URL identifying the publication in the public portal 


\title{
Testing of a Predictive Control Strategy for Balancing Renewable Sources in a Microgrid
}

\author{
Mattia Marinelli, Member, IEEE, Fabrizio Sossan, Student Member, IEEE, Giuseppe Tommaso Costanzo, \\ Student Member, IEEE, and Henrik W. Bindner, Member, IEEE
}

\begin{abstract}
This paper presents the design of a control strategy for the energy management of a grid-connected microgrid with local distributed energy resources as: $10-\mathrm{kW}$ photovoltaic plant, $11-\mathrm{kW}$ wind turbine, and 15-kW-190-kWh vanadium-based electric storage system. According to future regulations, the renewable energy producers will also have to provide a day-ahead hourly production plan. The overall idea is, by knowing the meteorological forecasts for the next $24 \mathrm{~h}$, to dispatch the microgrid in order to be able to grant the scheduled hourly production by means of proper management of the storage system. The usage of the storage system is, however, minimized by the energy management strategy. The system design is validated by experimental testing carried out in SYSLAB, a distributed power system test facility at Risø Campus, Technical University of Denmark.
\end{abstract}

Index Terms-Energy management, energy storage, photovoltaic (PV) power systems, testing, wind energy.

\section{INTRODUCTION}

I N MOST of today's power systems, fossil, hydro, and nuclear power plants provide the majority of the energy production. However, in the last three decades, factors such as the increase in global energy demand, the speculation on fossil fuels, and the global warming concerns have generated high interest in renewable energy sources. For example, in Denmark, wind power is planned to supply $50 \%$ of the demand by the year 2020, and in several member countries of the European Union, small scale feed-in systems have increased in popularity due to favorable regulations [1], [2].

In this context, the power systems will have to face challenges such as accommodating a highly variable and less controllable distributed energy production, in such a way that coordinating distributed energy resources (DERs) can improve the efficiency and the stability of the power systems, and increase the share of renewable energy [3], [4]. Depending on the type of distributed generation facilities and eventual flexible loads, the required control and operation strategies can be significantly different from the ones typically adopted in the traditional power systems. An emerging concept for controlling a group of DERs is the virtual power plant (VPP), which consists in managing the aggregation of devices as a single power plant. Depending on

Manuscript received July 13, 2013; revised October 28, 2013; accepted December 03, 2013.

The authors are with the Center for Electric Power and Energy, Department of Electrical Engineering, Technical University of Denmark (DTU), Risø Campus, 4000 Roskilde, Denmark (e-mail: matm@elektro.dtu.dk; faso@elektro.dtu.dk; guco@elektro.dtu.dk; hwbi@elektro.dtu.dk).

Color versions of one or more of the figures in this paper are available online at http://ieeexplore.ieee.org.

Digital Object Identifier 10.1109/TSTE.2013.2294194 the DERs' flexibility and connection point strength, the VPP can play a significant role in grid congestion management [5], [6].

Secure power systems' daily operation relies on the day-ahead dispatch of the different power plants. All the relevant resources are required to provide an hourly production plan. To increase the share of distributed generation from renewables, the photovoltaic (PV) plants and wind turbine (WT) plants will also be required, within time, to provide a predictable production. It means that every producer will have to provide a day-ahead production plan with hourly resolution, which is supposed to be granted within a given confidence interval. The DER production plan can be evaluated by using meteorological forecasts, which have an intrinsic uncertainty [7]. In such a setup, energy storage can help in meeting the hourly production plan. Having these plants properly dispatched allows the network operators to better manage the other producing sources. This is the approach considered in this work.

Since the production plan is on an hourly basis, the control algorithm target is energy dispatch rather than power dispatch. The energy storage is controlled in order to guarantee that at the end of each hour, the amount of energy fed in the grid equals the day-ahead predicted amount. An alternative control strategy that could be used for this purpose is to model predictive control, whose target is minimizing the sum of the squared residuals between the production plan and the actual one [8]-[10]. However, this approach has not been considered at this stage because short-term forecast of solar production is not available during the day of operation. The control strategy proposed in this study is computationally simple and aims at defining the main aspects, which have to be considered in order to manage the storage system.

The microgrid and energy management strategy are presented in Section II, the experimental testing are reported in Section III, and the conclusion and the future developments close the paper in Section IV.

\section{Microgrid AND Energy MANAGEMENT Description}

\section{A. Problem Approach}

The day before operation, an hourly energy production plan for the microgrid is defined. This plan is calculated by knowing the PV module layout information, the WT power curve, and the weather forecasts. During the operation day, the hourly production plan must be respected within $\pm 1 \%$. Deviations from the plan are mainly due to the forecast errors and inaccuracies in the model parameters. The storage system can be used to correct the deviations from the plan, but it is very crucial not to overuse it, 
because any charge/discharge cycle leads to energy losses and reduces the storage lifetime. For example, it has to be kept in mind that, during windy and cloudy days, there could be an excess of production in the first half an hour, followed by a lack of production in the second half. In this case, a good management strategy would foresee the use of the storage just in the last minutes, avoiding a depleting charge in the first half followed by a discharge in the second half. In contrast, the control action cannot be taken too late, otherwise the storage power capacity could limit the provision of energy in order to compensate the scheduling error.

The proposed experiment scenario represents a possible configuration of the power systems in the near future, where energy management systems will have to grant a predefined energy consumption pattern of small part of the system which, for instance, could be formed by both active sources and controllable loads. Because of its general formulation, the proposed approach can be extended at other microgrid setups such as the ones described in [11]. An early stage of this strategy has been described and tested in the previous work, aimed at controlling both from a power and an energy perspective, a renewable generation set composed by a small WT and a storage system [12].

\section{B. Microgrid Layout}

The proposed approach is experimentally validated in SYSLAB, which is a small-scale power system consisting of real power components interconnected by a three-phase $400-\mathrm{V}$ power grid, and some communication and control nodes interconnected by a dedicated network, all distributed over the Risø Campus of the Technical University of Denmark (DTU). The generation set is connected to the local medium-voltage distribution network and is fully controllable by the SCADA [13].

The microgrid layout and the energy management conceptual model of the system are shown in Fig. 1. The 10-kW PV plant is formed by two equal size sections consisting of thin film modules in copper indium selenium and in polycrystalline modules. The plant is interfaced to the low-voltage network through a threephase inverter. The thin film part is formed by 84 modules with $60-\mathrm{W}$ nominal power $(-2 \% /+8 \%$ tolerance) arranged in 6 parallel strings of 14 modules. The crystalline section is formed by 1 string of 22 modules $230-\mathrm{W}$ nominal power $(0 /+3 \%$ tolerance).

The 11-kW Gaia turbine is a two bladed, 13-m diameter, fixed pitch stall control, asynchronous generator equipped WT. The cut-in wind speed is $2.5 \mathrm{~m} / \mathrm{s}$, whereas the nominal wind speed is $11 \mathrm{~m} / \mathrm{s}$. The squirrel-cage asynchronous generator is directly connected to the $400-\mathrm{V}$ network.

The storage system is a Vanadium redox battery, which is formed by a series of three stacks composed of 42 cells each and is equipped with two tanks containing 65001 of Vanadium solution, each leading to a theoretical storing capacity of $320 \mathrm{kWh}$; limited by the battery management system to $190 \mathrm{kWh}$. The storage is equipped with an inverter capable of providing up to $\pm 15 \mathrm{~kW}$ and $+12 \mathrm{kVAr}$, and it is able to ramp from full power charge to full power discharge within $2 \mathrm{~s}$. For the study proposed, it is interesting to analyze the energy performance with

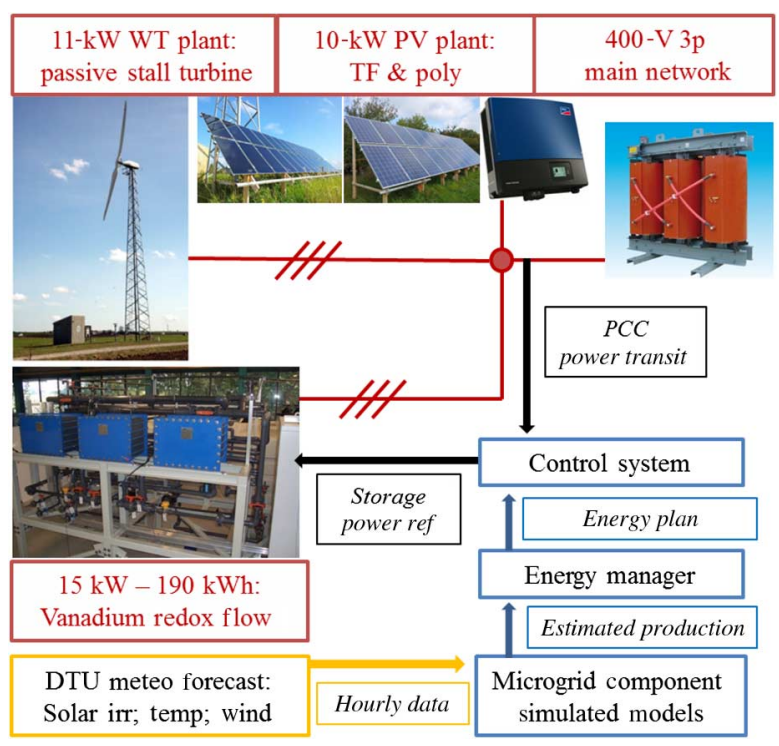

Fig. 1. Microgrid layout and energy management block diagram. In the upper part of the picture, with red blocks, the power system components are denoted. The energy management diagram is identified by the blue blocks.

a power size smaller than the size of the whole generation system, equal to $21 \mathrm{~kW}$. Therefore, the storage inverter will be limited in the output to a maximum power of $\pm 5 \mathrm{~kW}$. The choice of this rating will be explained subsequently.

The storage system is connected in parallel to the two generation plants, and the overall system is connected to the local main network. At the point of common coupling (PCC), the power transit is measured every second and integrated over the time in order to calculate the cumulated energy within the hour. This value is the feedback used by the control system, realized in MATLAB-Simulink, in order to set the reference power to the storage, according to the energy schedule evaluated by the microgrid model and the energy manager.

\section{Energy Management Concept}

The energy manager provides the day-ahead production plan according to the weather forecasts. Fig. 1 shows that the meteorological information, which means the solar irradiance on the horizontal plane, the wind speed at $10 \mathrm{~m}$ above the ground and the air temperature at $2 \mathrm{~m}$ above the ground are the main inputs of the energy management system. The meteorological hourly data are provided by the DTU Wind Energy Department [14]. Forecasts are given two times per day for the following $48 \mathrm{~h}$ : around 9 A.M., the 48 hourly series starting at 12 GMT is given, whereas around 9 P.M., the one starting at 24 GMT. For this study, the morning forecasts are used, since the idea is to provide the microgrid production plan before the closure of the day-ahead market at midday.

A statistical analysis of the error committed by the forecasts has been done. Fig. 2 shows the results of 6 months of comparison between the forecasted values of wind speed and solar irradiance and the respective historical data. The mean values are equal to $1.0 \mathrm{~m} / \mathrm{s}$ and $34 \mathrm{~W} / \mathrm{m}^{2}$, and the standard deviations are $2.9 \mathrm{~m} / \mathrm{s}$ and $258 \mathrm{~W} / \mathrm{m}^{2}$, respectively. Since the forecasts are slightly biased, a statistical model could be used to remove this problem [15]. 

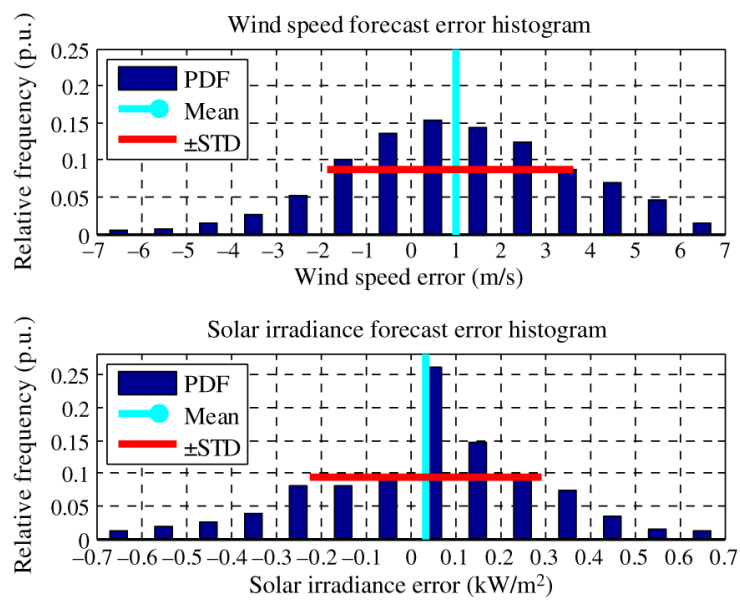

Fig. 2. First plot: wind speed forecast error diagram. Second plot: solar irradiance forecasts error diagram.

In order to evaluate the renewable sources production, which means the predicted output of PV and WT, the hourly weather data are used as inputs for the simulated models realized in Simulink. The electromechanical dynamics are neglected in the resource models, since the control objective is defined with respect to the energy and not to the power quality.

The estimated production profile of both PV and WT is evaluated and it constitutes the input to the energy manager, which computes the energy plan. Even if the energy management aims at controlling the hourly energy production, the control action is performed at 1-s discretized time steps: it means that every second, the cumulated energy at the PCC is compared with the energy plan. The "Energy Ref," the blue curve of Fig. 3, which is used to design the two control bands, forms the energy plan; it is zero at the beginning of the time window and is equal to the planned energy value at the end of the hour.

The red and the green dashed curves are the control bands: whenever the system energy state, which is the cumulated microgrid energy production within the hour, exceeds the upper or the lower band, a negative or positive set-point is sent to the storage; the more the distance from the objective value, the deeper the charge/discharge required. On the contrary, if the system energy state matches the scheduled one or it is inside the band, no charge/discharge actions are performed. The opening of the lines, which means the distance between the upper and the lower bands with reference to the "Energy Ref" curve, determines the stiffness of the control. In this case, the initial opening is $\pm 10 \%$ of the final energy value and it is progressively reduced in order to guide the microgrid energy production [16].

\section{Microgrid Component Models}

In order to evaluate the PV and the WT production, proper models have been developed in Simulink.

The PV model, shown in Fig. 4, is formed by several blocks, where the equations for the description on the movement of the Sun and the evaluation of the efficiency chain in the energy conversion process of the PV module, starting from the solar irradiance and getting to the ac output, are implemented [17], [18].

The panel model has been characterized in accordance with the data provided by the manufacturers and considering the

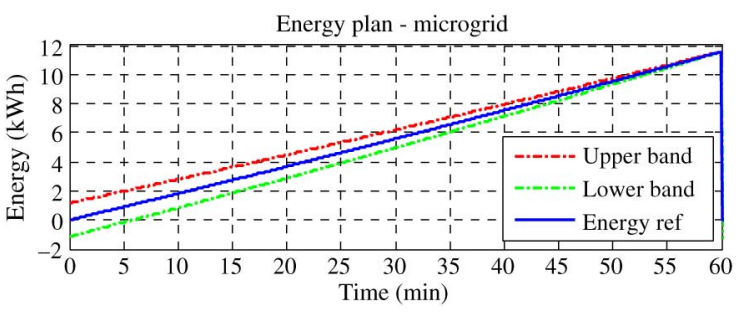

Fig. 3. Microgrid energy plan: reference energy (blue), lower band (dashed green), and upper band (dashed red).

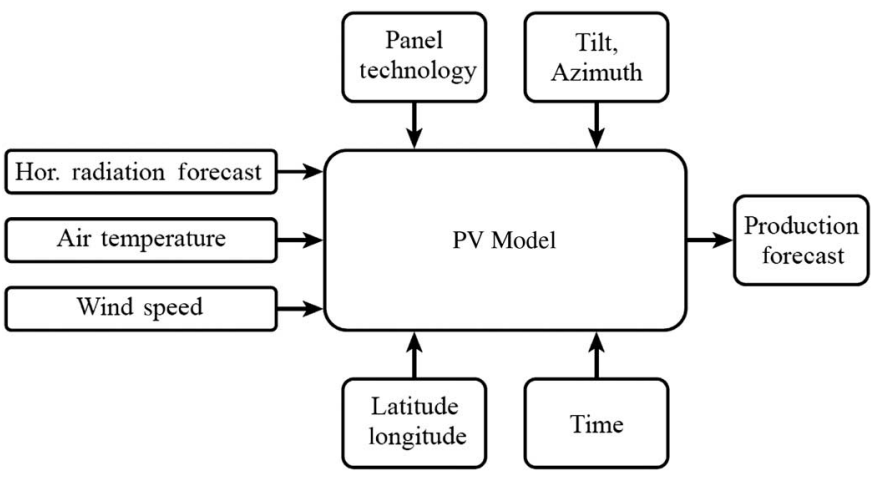

Fig. 4. PV model block diagram concept used to evaluate the ac production by knowing the weather forecasts and the plant location and technology.

experience acquired from the PV installed in the facility. The dc power produced by the modules mainly depends on the incident solar irradiance and on the panel temperature, which, for instance, is the function of air temperature, wind speed, and irradiance itself. The dependence of the panel output with different sunlight intensities and the dependence in function of the temperature are computed in order to evaluate the reduction from the nominal efficiency, knowing that the nominal data are provided for standard meteorological conditions $\left(1000 \mathrm{~W} / \mathrm{m}^{2}\right.$ and $25^{\circ} \mathrm{C}$ ). The dynamics of the inverter and of the maximum power point tracking are not considered.

The analyses have been conducted on several days of the year, and the comparison between the historical production for a sunny day and the output with the model is reported in Fig. 5. The first plot shows the data with 1-min sample, whereas the second reports the hourly averages. On the day analyzed, the historical production is equal to $64.1 \mathrm{kWh}$, whereas the one estimated by the model is equal to $63.5 \mathrm{kWh}$. The overall daily difference is $0.6 \mathrm{kWh}$, which referred to the forecasted one is equal to $1.0 \%$; whereas the sum of the hourly errors regardless of sign is $4.4 \mathrm{kWh}$ (relative value equal to $6.9 \%$ ).

The WT turbine model is much simpler and it basically consists in the static power curve of the turbine, which has been experimentally derived from historical production measurements and is reported in Fig. 6. Therefore, the model input is the forecasted wind speed at $10 \mathrm{~m}$ above the ground. The WT power characteristic is modeled by a fifth-order polynomial function of the wind speed and the parameters are listed in Table I.

Also, for the WT, 1 day comparison between the historical production and the output with the model is reported in Fig. 7. On the day analyzed, the historical production is equal to $114.0 \mathrm{kWh}$, whereas the one estimated by the model is equal to $114.4 \mathrm{kWh}$. 
This article has been accepted for inclusion in a future issue of this journal. Content is final as presented, with the exception of pagination.
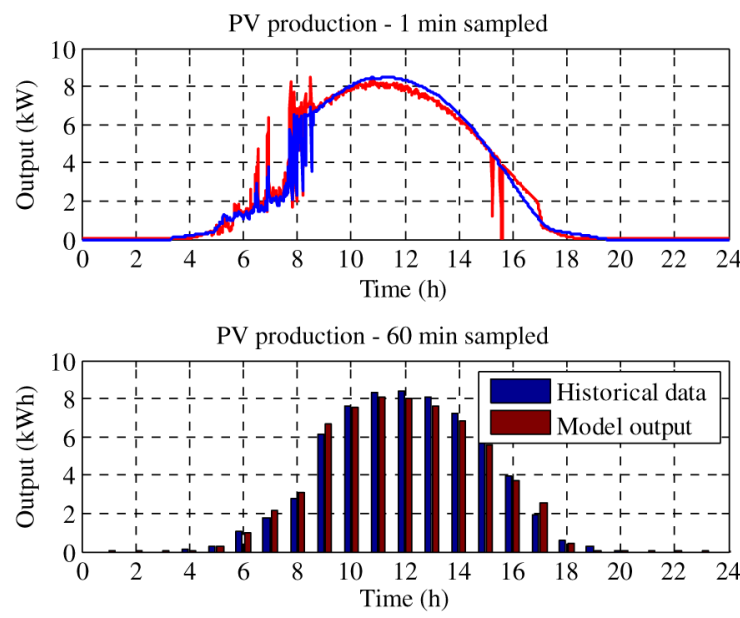

Fig. 5. PV model output (red) and historical data (blue) for the day: 6 July 2013 reported with different time samples $(1$ and $60 \mathrm{~min})$. The measurements are referred to the ac side. Time in GMT.

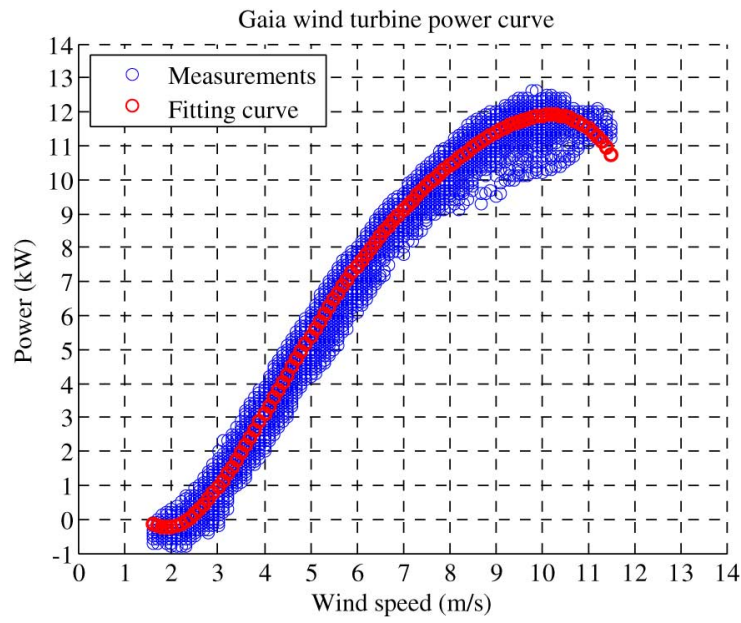

Fig. 6. Gaia WT power measurements in blue and experimentally derived power curve in red.

The overall daily difference is $-0.4 \mathrm{kWh}$, which referred to the forecasted one is equal to $-0.3 \%$; whereas the sum of the hourly errors regardless of sign is $1.4 \mathrm{kWh}$ (relative value equal to $1.2 \%)$.

\section{E. Concerning the Power and the Energy Sizing of the Storage}

The design of the control bands introduced in Section II-C, together with the maximum deviation allowed from the production plan, has an impact on both the storage power and energy. As foretold, the two main variables that affect the sizing of the storage are the precision and accuracy of the meteorological forecast and of the PV and WT models.

The opening of the control bands shown in Fig. 3, the distance between the upper and the lower bands, determines the stiffness of the control. In the considered setup, the control bands are set to $10 \%$, meaning that the lower band (the green line shown in Fig. 3) crosses at the sixth minute of the time axis. The power size of the storage affects the hourly energy error. This means that a storage inverter of $5 \mathrm{~kW}$ should be able, in case of null production of the microgrid, to release full power for the remaining $54 \mathrm{~min}$, leading
TABLE I

Gaia WT Power Curve Polynomial Parameters

\begin{tabular}{c|c|c|c|c|c}
\hline$P_{1} \cdot x^{5}$ & $P_{2} \cdot x^{4}$ & $P_{3} \cdot x^{3}$ & $P_{4} \cdot x^{2}$ & $P_{5} \cdot x^{1}$ & $P_{6} x^{0}$ \\
\hline-1.18802 & 41.43729 & -569.070 & 3665.9 & -8778.7 & 6587.9 \\
\hline
\end{tabular}
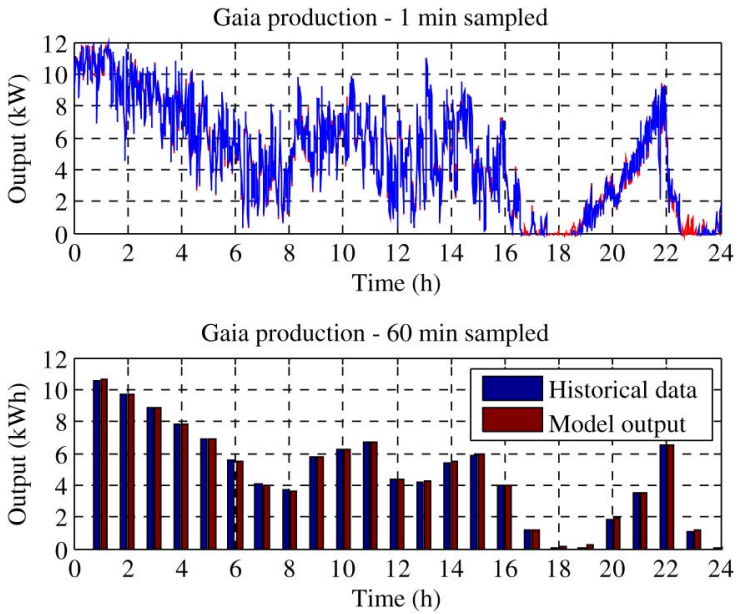

Fig. 7. WT output (red) and historical data (blue) for the day: 22 June 2013 reported with different time samples (1 and $60 \mathrm{~min})$. Time in GMT.

to a maximum energy of $4.5 \mathrm{kWh}$. Considering a microgrid maximum hourly production of $21 \mathrm{kWh}$, which means full power output from both PV and WT, with this control band setup, the storage is able to compensate production errors up to $21 \%$ of the microgrid hourly production.

Now, it has to be taken into account that quite rarely the microgrid will be producing the maximum power for $1 \mathrm{~h}$ and at the same time they have the weather forecasts totally wrong. Therefore, an opportune tuning of the bands slope is considered here. By analyzing 6 months of historical data of weather forecasts and real wind and solar production, it has been possible to compute the error distribution on the predicted energy production. The analyses showed that the distribution of energy production errors has a mean value close to zero and standard deviation close to $21 \%$ of the nominal generation power. The choice of sizing the storage power to $5 \mathrm{~kW}$ should grant deviation compensations in the $68 \%$ of the events.

The sizing of the storage capacity depends on the coherence of the forecast errors instead. It can be easily noted that in case of alternate hourly errors, the storage alternatively charges and discharges so that the depletion of the state of charge depends mainly on the storage internal inefficiencies. Therefore, the storage energy rating could be relatively small. If the error has the same sign for the whole day, then the storage energy sizing criteria need to be revisited. At the present stage, no analyses have been done regarding this aspect since right now, it is interesting to analyze the experimental behavior of the proposed strategy rather than performing a storage technical-economical evaluation.

\section{F. Control System Sensitivity}

The sensitivity of the controller is chosen in order to have the storage to store/release the maximum power $P_{\max }$, if the relative energy error $e$ is equal or greater to $1 \%$. The relative energy error is the difference between the system energy state and the control 
This article has been accepted for inclusion in a future issue of this journal. Content is final as presented, with the exception of pagination.

TABLE II

Storage Power Reference Table

\begin{tabular}{cc|cc}
\hline $\begin{array}{c}\text { Upper relative } \\
\text { energy error } \%\end{array}$ & $\begin{array}{c}\text { Storage reference } \\
\text { power }\end{array}$ & $\begin{array}{c}\text { Lower relative } \\
\text { energy error } \%\end{array}$ & $\begin{array}{c}\text { Storage reference } \\
\text { power }\end{array}$ \\
\hline$e_{\text {up }} \leq 0 \%$ & 0 & $e_{\text {down }} \leq 0 \%$ & 0 \\
\hline $0<e_{\text {up }} \leq 0.2$ & 0 & $0<e_{\text {down }} \leq 0.2$ & 0 \\
\hline $0.2<e_{\text {up }} \leq 0.4$ & $-20 \% P_{\max }$ & $0.2<e_{\text {down }} \leq 0.4$ & $20 \% P_{\max }$ \\
\hline $0.4<e_{\text {up }} \leq 0.6$ & $-40 \% P_{\max }$ & $0.4<e_{\text {down }} \leq 0.6$ & $40 \% P_{\max }$ \\
\hline $0.6<e_{\text {up }} \leq 0.8$ & $-60 \% P_{\max }$ & $0.6<e_{\text {down }} \leq 0.8$ & $60 \% P_{\max }$ \\
\hline $0.8<e_{\text {up }} \leq 1$ & $-80 \% P_{\max }$ & $0.8<e_{\text {down }} \leq 1$ & $80 \% P_{\max }$ \\
\hline$e_{\text {up }} \geq 1 \%$ & $-P_{\max }$ & $e_{\text {down }} \geq 1 \%$ & $P_{\max }$ \\
\hline \multicolumn{5}{r}{}
\end{tabular}
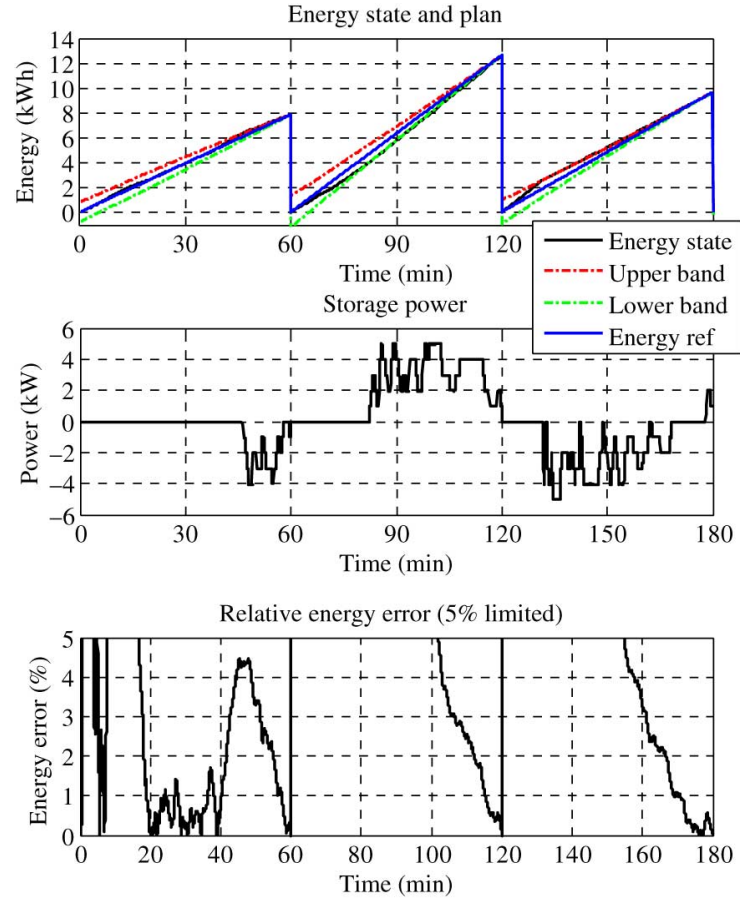

Fig. 8. First plot: energy plan and system state. Second plot: storage output. Third plot: relative energy error (the values greater than $5 \%$ are not shown).

bands. Two energy errors can be identified depending on the crossing of the upper or the lower band.

1) The first error $e_{\mathrm{up}}$ is the difference between the system energy state and the upper control band divided by the upper control band value. This error triggers a storage charge.

2) The second error $e_{\text {down }}$ is the difference between the system energy state and the lower control band divided by the lower control band value. This error triggers a storage discharge.

If the error amplitude is within $0 \%$ and $1 \%$, the storage power set-point is changed by five discrete steps with $20 \%$ amplitude. Table II provides an overview of the storage power reference. The storage reference power signals are triggered according to a relay logic, e.g., if the error goes above $0.2 \%$, then the reference power becomes $20 \%$ and the value is hold unless the error goes below $0 \%$, thus taking the reference power to $0 \%$.

\section{EXPERIMENTAL TESTING}

\section{A. Experimental Procedure}

The testing days reported are the July 3, 2013, which was a windy day with frequent cloud passages, and the July 7, 2013,
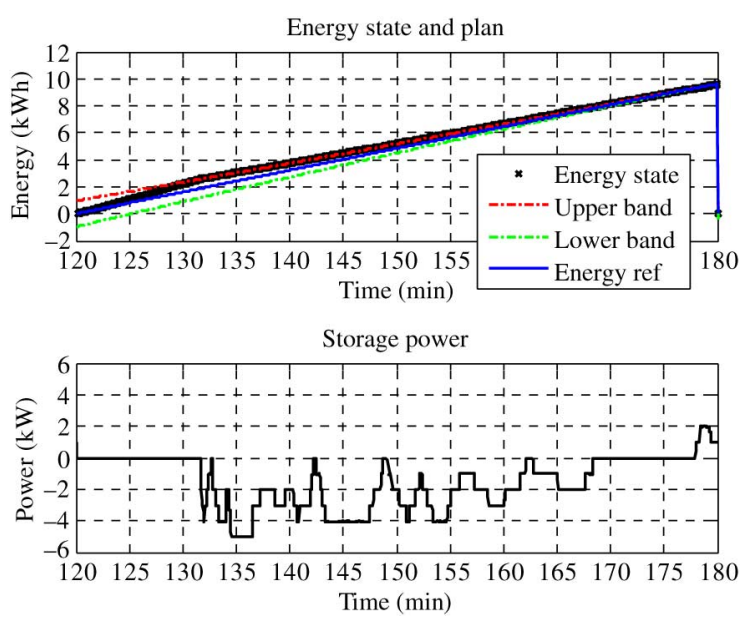

Fig. 9. First plot: energy plan and system energy state in the last hour. Second plot: storage output.
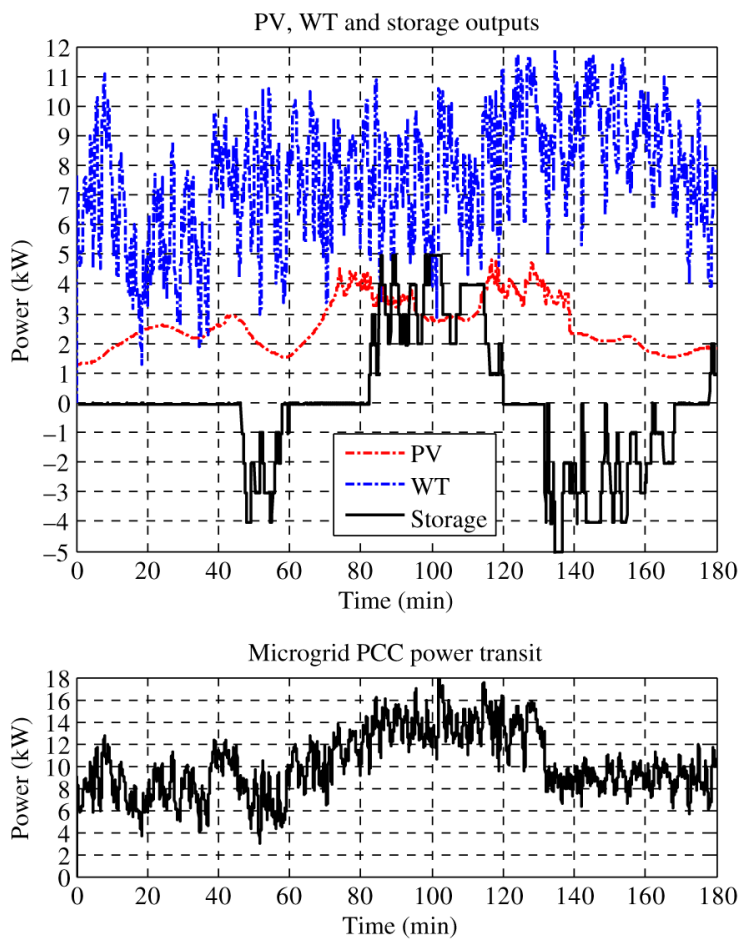

Fig. 10. First plot: PV, WT, and storage outputs. Second plot: microgrid PCC power transit (sum of PV, WT, and storage).

which was a sunny day with little wind. The experimental process is explained here.

1) The meteorological forecast data (solar irradiance, wind speed, and air temperature) of the studied day are used to evaluate the PV and WT output. The day-ahead forecasts, the forecasts given at 9 A.M. on July 2, 2013 (for the experiment run on July 3, 2013), are taken into consideration.

2) The PV and WT model outputs are used to build the forecasted energy plan for the studied day (July 3, 2013).

3) The microgrid setup is prepared; the PC with the Simulink controller, aimed at managing the storage system, is connected to the SYSLAB facility; and the experiment runs. 
This article has been accepted for inclusion in a future issue of this journal. Content is final as presented, with the exception of pagination.

TABLE III

Microgrid Performances for the Experiments on July 3, 2013 and July 7, 2013

\begin{tabular}{|c|c|c|c|c|c|c|c|c|c|c|c|}
\hline \multirow[b]{2}{*}{ GMT hours } & \multicolumn{4}{|c|}{3 July - 13:00-16:00 GMT } & \multicolumn{7}{|c|}{7 July - 9:00-15:00 GMT } \\
\hline & $13-14$ & $14-15$ & $15-16$ & $13-16$ & $9-10$ & $10-11$ & $11-12$ & $12-13$ & $13-14$ & $14-15$ & $9-15$ \\
\hline PV+WT forecasted (kWh) & 7.85 & 12.61 & 9.61 & 30.07 & 11.56 & 12.78 & 12.82 & 12.40 & 11.46 & 9.67 & 70.69 \\
\hline PV+WT produced (kWh) & 8.49 & 10.75 & 11.35 & 30.58 & 8.90 & 9.78 & 9.41 & 9.42 & 9.58 & 6.93 & 54.02 \\
\hline PV+WT error $(\mathrm{kWh})$ & 0.64 & -1.86 & 1.74 & $4.24^{\mathrm{a}}$ & -2.66 & -3.00 & -3.41 & -2.98 & -1.88 & -2.73 & $-16.66^{a}$ \\
\hline Storage usage (kWh) & -0.51 & 2.48 & -4.10 & $7.09^{\mathrm{a}}$ & 2.56 & 5.36 & 8.63 & 11.56 & 13.36 & 16.00 & 57.47 \\
\hline PCC energy transit (kWh) & 7.88 & 12.60 & 9.61 & 30.08 & 11.48 & 12.60 & 12.70 & 12.38 & 11.38 & 9.57 & 70.11 \\
\hline PCC energy absolute error (kWh) & 0.027 & -0.014 & -0.003 & $0.044^{\mathrm{a}}$ & -0.08 & -0.18 & -0.12 & -0.03 & -0.07 & -0.10 & $-0.58^{\mathrm{a}}$ \\
\hline PCC energy relative error (\%) & 0.35 & -0.11 & -0.03 & $0.15^{\mathrm{b}}$ & -0.71 & -1.41 & -0.90 & -0.22 & -0.60 & -0.99 & $0.80^{\mathrm{b}}$ \\
\hline
\end{tabular}

${ }^{a}$ Calculated as the sum of the hourly errors regardless of sign.

${ }^{\mathrm{b}}$ Calculated as the weighted average of the hourly errors regardless of sign.

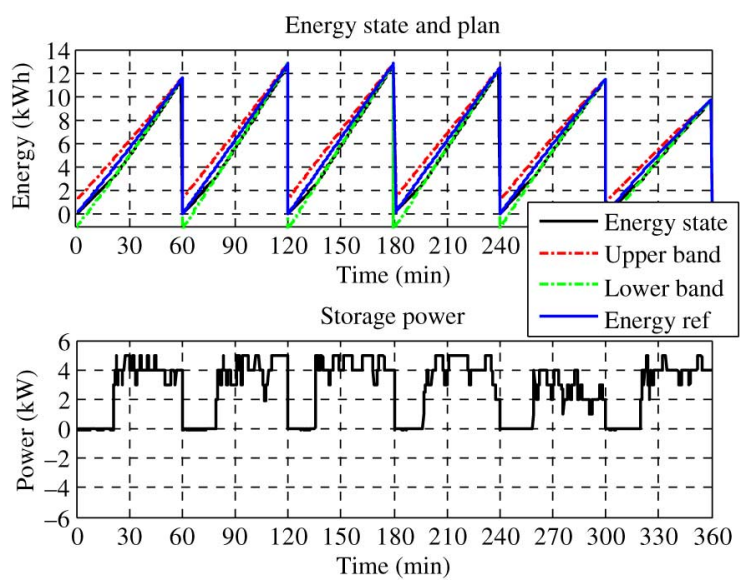

Fig. 11. First plot: energy plan and system state. Second plot: storage output.

\section{B. Experiment on July 3, 2013-13:00 to 16:00 GMT}

The experiment starts at 13:00 GMT (15:00 local time) and lasts for $3 \mathrm{~h}$. The overall energy plan, which means the expected production for PV and WT, for the 3-h experiment is shown in the first plot of Fig. 8. The microgrid energy production can also be observed in this plot and can be seen that it is always kept inside the control bands or quite close to them. The storage, whose output is depicted in the second plot of Fig. 8, is, therefore, able to compensate the deviations from the predicted production.

The relative deviation from the expected production, which means the difference between the production and the forecasts, referred to the energy plan is reported in the third plot of Fig. 8. As it can be seen at the end of every hour, the storage system is able to successfully take the microgrid energy production to the desired value. For the sake of clarity, a zoom of the plot with the energy plan and the energy state is reported in Fig. 9. It can be observed that the excess of production takes the energy state to cross the upper band at the 130th min, triggering a storage charge, which is visible in the second plot of Fig. 9.

The power profiles of the different components can be observed in the first plot of Fig. 10, whereas the overall microgrid production that means the power transit at the $\mathrm{PCC}$ is reported in the second plot.
The relevant system performances data are reported in Table III. The evaluations reported are calculated as follows.

1) PV + WT forecasted is the forecasted hourly production; it is the value of the energy plan at the end of the hour.

2) PV $+\mathrm{WT}$ produced is the hourly energy produced by the renewable sources.

3) PV + WT error is the difference between the energy produced and forecasted. The error is positive if there is an excess of production.

4) Storage usage is the total work of the storage: the sum of charge and discharge, regardless of the sign.

5) PCC energy transit is the hourly production of the whole microgrid; thus, PV, WT, and storage, including the cable losses (almost negligible due to their size).

6) PCC energy absolute error is the difference between the microgrid PCC transit and the forecasted production.

7) PCC energy relative error is the PCC energy error relative to the PV + WT forecasted.

It can be seen that the forecasted energy production, considering the whole $3 \mathrm{~h}$ is extremely good. The forecasted energy accounted for $30.07 \mathrm{kWh}$, whereas the effectively energy produced by PV and WT accounted for $30.58 \mathrm{kWh}$ (i.e., $1.7 \%$ greater). However, if the hourly difference between the expected energy production and the effective one is analyzed, it can be seen that the cumulated absolute error is $4.24 \mathrm{kWh}$ (i.e., $14.1 \%$ with reference to the $\mathrm{PV}+\mathrm{WT}$ forecasted energy, equal to $30.07 \mathrm{kWh}$ ). In order to have this deviation compensated, the storage system is required to provide both charges and discharges for a total energy of $7.09 \mathrm{kWh}$. By doing so, the energy relative error drops to $0.044 \mathrm{kWh}$ (i.e., $0.15 \%$ with reference to the $\mathrm{PV}+\mathrm{WT}$ forecasted energy, equal to $30.07 \mathrm{kWh}$ ).

\section{Experiment on July 7, 2013-09:00 to 15:00 GMT}

The experiment starts at 09:00 GMT (11:00 local time) and lasts for $6 \mathrm{~h}$. Fig. 11 reports the overall energy plan along with the power output of the storage. It is straightforward to note that the forecasts were rather optimistic; however, the storage succeeds in managing the microgrid energy production.

The power profiles of the different components can be observed in Fig. 12. The overall microgrid production, which means the power transit at the PCC, is reported in Fig. 13; the storage power steps can be easily identified in the PCC power 


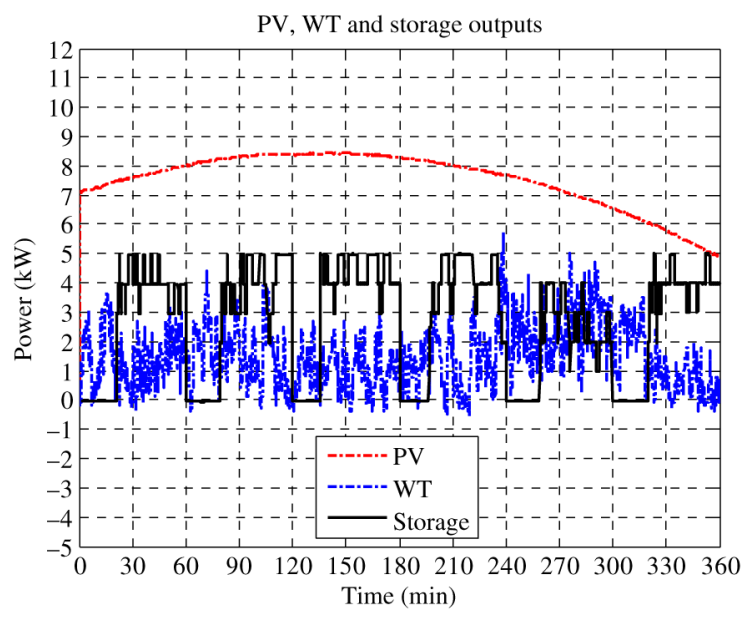

Fig. 12. PV, WT, and storage outputs.
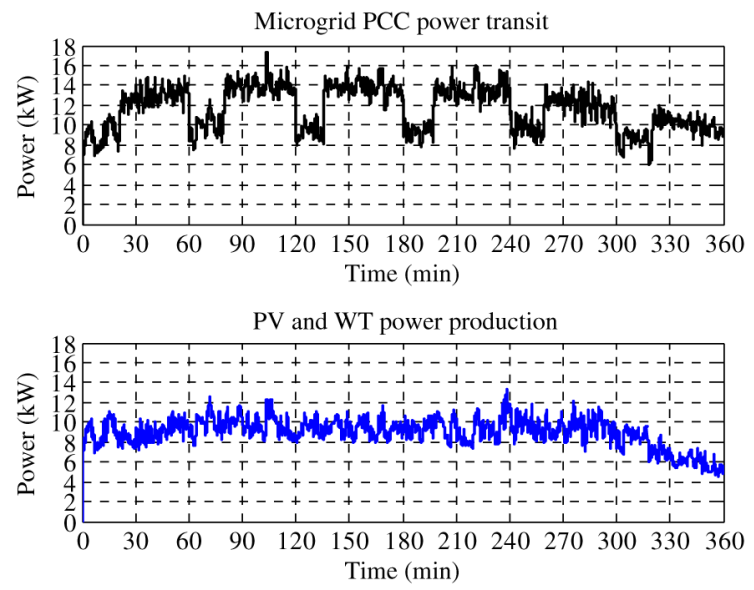

Fig. 13. First plot: microgrid PCC power transit (sum of PV, WT, and storage). Second plot: PV and WT power production.

profile. However, the storage output is not changing significantly the microgrid power production profile, because the rating of the storage is relatively small compared to the generation capacity and the power output smoothing is not pursued.

At this stage, the microgrid is connected to a strong network, thus these sudden changes are not jeopardizing the system stability. However, in case of weak networks or islanded systems, the effects on voltages and frequency have to be properly taken into account.

Similar to the previous experiment, the relevant system performances data are summarized in Table III. Also, from the numbers, a quite large errors can be seen (around $-25 \%$ ) in terms of energy forecasts. Nevertheless, the PCC energy relative error is kept below $1 \%$ except that in the second hour (10-11 GMT), where it gets $-1.14 \%$.

\section{Conclusion and Future DeVelopments}

The management of the energy production of energy systems and renewable generation sets will get more and more importance in the near future. The correct prediction of the expected production will be crucial in order to be able to manage the overall system resources. Improving the forecast techniques is of great importance; however, errors cannot be totally avoided. The compensation of these errors will be critical and a proper management of the controllable resources, such as storage systems or controllable loads, is essential.

This paper proposed a predictive management strategy capable of controlling a storage system, power limited to $5 \mathrm{~kW}$, in order to have the forecasted energy production plan of a microgrid, formed by a $10-\mathrm{kW}$ PV and an $11-\mathrm{kW}$ WT, granted. The overall idea consists in, by knowing the meteorological forecast for the next $24 \mathrm{~h}$, controlling the storage system in order to compensate the hourly deviations from the day-ahead energy plan, by minimizing the storage usage. It has been proved that this management strategy is capable of compensating the deviations from the forecasted energy plan.

A first evaluation of the correlation between the meteorological forecasts errors and the sizing in terms of power and energy of the storage is analyzed even if deeper analyses are needed. The range of experiments will be extended across the days, taking also the advantage of the fact that the whole system can be studied in the simulated environment. Finally, further analysis will aim at extending the described strategy in a larger microgrid setup, including building appliances, such as heating systems, water heaters, and electric vehicles.

\section{REFERENCES}

[1] K. F. Katiraei and J. R. Agüero, "Solar PV integration challenges," IEEE Power Energy Mag., vol. 9, no. 3, pp. 62-71, May/Jun. 2011.

[2] J. V. Appen, M. Braun, T. Stetz, K. Diwold, and D. Geibel, "Time in the Sun: The challenge of high PV penetration in the German electric grid," IEEE Power Energy Mag., vol. 11, no. 2, pp. 55-64, Mar. 2013.

[3] T. Ackermann, J. R. Abbad, I. M. Dudurych, I. Erlich, H. Holttinen, J. R. Kristoffersen et al., "European balancing act," IEEE Power Energy Mag., vol. 5, no. 6, pp. 90-103, Nov./Dec. 2007.

[4] S. Grillo, M. Marinelli, S. Massucco, and F. Silvestro, "Optimal management strategy of a battery-based storage system to improve renewable energy integration in distribution networks," IEEE Trans. Smart Grid, vol. 3, no. 2, pp. 950-958, Jun. 2012.

[5] F. Katiraei, R. Iravani, N. Hatziargyriou, and A. Dimeas, "Microgrids management," IEEE Power Energy Mag., vol. 6, no. 3, pp. 54-65, May/Jun. 2008.

[6] C. A. Hill, M. C. Such, C. Dongmei, J. Gonzalez, and W. M. Grady, "Battery energy storage for enabling integration of distributed solar power generation," IEEE Trans. Smart Grid, vol. 3, no. 2, pp. 850-857, Jun. 2012.

[7] E. Lorenz, J. Hurka, D. Heinemann, and H. G. Beyer, "Irradiance forecasting for the power prediction of grid-connected photovoltaic systems," IEEE J. Sel. Top. Appl. Earth Observ. Remote Sens., vol. 2, no. 1, pp. 2-10, Mar. 2009.

[8] S. Teleke, M. E. Baran, S. Bhattacharya, and A. Q. Huang, "Optimal control of battery energy storage for wind farm dispatching," IEEE Trans. Energy Convers., vol. 25, no. 3, pp. 787-794, Sep. 2010.

[9] F. Sossan, A. M. Kosek, S. Martinenas, M. Marinelli, and H. W. Bindner, "Scheduling of domestic water heater power demand for maximizing PV self-consumption using model predictive control," in Proc. 4th IEEE PES Int. Conf. Exhib. Innov. Smart Grid Technol. (ISGT Eur.), Copenhagen, Denmark, 2013, pp. 1-5.

[10] E. Perez, H. Beltran, N. Aparicio, and P. Rodriguez, "Predictive power control for PV plants with energy storage," IEEE Trans. Sustain. Energy, vol. 4, no. 2, pp. 482-490, Apr. 2013.

[11] B. Kroposki, R. Lasseter, T. Ise, S. Morozumi, S. Papatlianassiou, and N. Hatziargyriou, "Making microgrids work," IEEE Power Energy Mag., vol. 6, no. 3, pp. 40-53, May/Jun. 2008.

[12] F. Baccino, M. Marinelli, F. Silvestro, O. Camacho, F. Isleifsson, and P. Nørgård, "Experimental validation of control strategies for a microgrid test facility including a storage system and renewable generation sets," in Proc. Integr. Renewables Distrib. Grid CIRED 2012 Workshop, Lisbon, Portugal, May 29-30, 2012, pp. 1-4. 
[13] O. Gehrke and H. W. Bindner, "Building a test platform for agents in power system control: Experience from SYSLAB," in Proc. Int. Conf. Intell. Syst. Appl. Power Syst. (ISAP 2007), Kaohsiung, Taiwan, 2007, pp. 1-5.

[14] A. N. Hahmann, D. Rostkier-Edelstein, T. T. Warner, F. Vandenberghe, Y. Liu, R. Babarsky, and S. P. Swerdlin, "A reanalysis system for the generation of mesoscale climatographies," J. Appl. Meteorol. Climatol., vol. 49, no. 5, pp. 954-972, May 2010.

[15] P. Bacher, H. Madsen, and H. A. Nielsen, "Online short-term solar power forecasting," Sol. Energy, vol. 83, no. 10, pp. 1772-1783, Oct. 2009.

[16] F. Baccino, S. Grillo, M. Marinelli, S. Massucco, and F. Silvestro, "Power and energy control strategies for a vanadium redox flow battery and wind farm combined system," in Proc. 2nd IEEE PES Int. Conf. Exhib. Innov. Smart Grid Technol. (ISGT Eur.), Manchester, U.K., 2011, pp. 1-8.

[17] E. Skoplaki, A. G. Boudouvis, and J. A. Palyvos, "A simple correlation for the operating temperature of photovoltaic modules of arbitrary mounting," Sol. Energy Mater. Sol. Cell, vol. 92, no. 11, pp. 1393-1402, Nov. 2008

[18] M. Marinelli, F. Sossan, F. Isleifsson, G. T. Costanzo, and H. W. Bindner, "Day-ahead scheduling of a photovoltaic plant by the energy management of a storage system," in Proc. 48th Int. Univ. Power Eng. Conf. (UPEC), Dublin, Ireland, 2013, pp. 1-6.

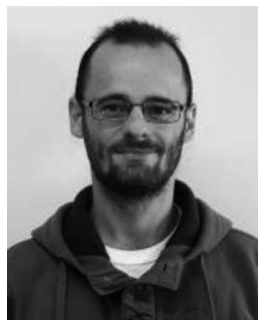

Mattia Marinelli (S'10-M'12) was born in Genova, Italy, in 1983. He received the B.Sc. and M.Sc. degrees in electrical engineering from the University of Genova, Genova, in 2005 and 2007, respectively. $\mathrm{He}$ received the Ph.D. degree with European label in power systems from the University of Genova, in March 2011.

Since September 2012, he has been with the Technical University of Denmark (DTU), Roskilde, Denmark. His research interests include power system integration studies, wind and solar data analysis, demand-side management, distributed generators, and electrochemical storages modeling.

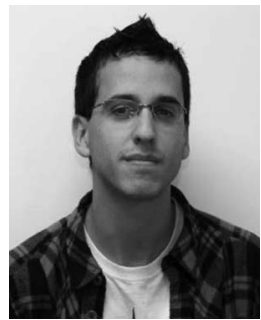

Fabrizio Sossan (S'10) was born in Genova, Italy, in 1985. He received the B.Sc. and M.Sc. degrees in robotic and control engineering from the University of Genova, Genova, Italy, in 2007 and 2010, respectively. He is currently working toward the Ph.D. degree at the Technical University of Denmark (DTU), Roskilde, Denmark.

His main research interests include mathematical modeling, control, optimization, and time series analysis.

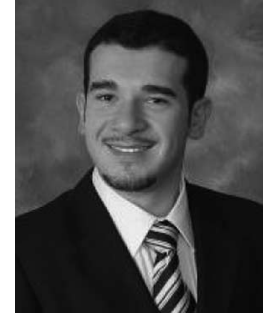

Giuseppe Tommaso Costanzo (S'09) was born in Catania, Italy, in 1986. He received the B.Sc. and M.Sc. degrees in control engineering from Politecnico di Milano, Milano, Italy, in 2009 and 2011, respectively, and the M.A.Sc. degree in electrical engineering from École Polytechnique de Montréal, Montréal, Canada, in 2011. He is currently working toward the Ph.D. degree at the Technical University of Denmark (DTU), Roskilde, Denmark.

His research interests include the application of optimization, model predictive control, machine learning to energy management in smart buildings, and demand-side management.

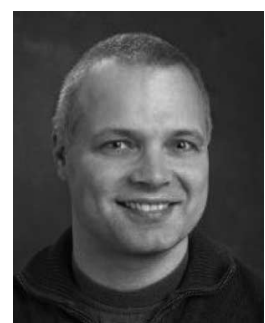

Henrik W. Bindner (M'10) was born in Copenhagen, Denmark, in 1964. He received the M.Sc. degree in electrical engineering from the Technical University of Denmark (DTU), Roskilde, Denmark, in 1988.

Since 1990, he has been with Risø, DTU. Currently, he is a Senior Scientist and Head of the Scientific Group, Energy Systems Operations and Management, in DTU. In the last years, he has been focusing on developing technologies and control schemes enabling DER units to participate in the control of the power system. One of his main activities has been participation in establishing the experimental facility SYSLAB. 